\title{
On the teroxide of gold
}

\section{Figuier}

To cite this article: M. Figuier (1844) On the teroxide of gold, Philosophical Magazine Series 3, 25:167, 394-395, DOI: $10.1080 / 14786444408645022$

To link to this article: http://dx.doi.org/10.1080/14786444408645022

曲 Published online: 30 Apr 2009.

Submit your article to this journal

Џ Article views: 2

Q View related articles $₫$ 


\section{Gold .... 74 in 100 \\ Azote.... 9.5 in 100}

These numbers are represented by the formula $\mathrm{Au}^{2} \mathrm{O}^{3}+2\left(\mathrm{AzH}^{3}\right)$ $+\mathrm{HO}$, which represents the preceding compound as hydrated, and which requires

$$
\begin{array}{ll}
\text { Gold .... } & 75 \text { in } 100 \\
\text { Azote .. } & 10 \text { in } 100
\end{array}
$$

It can scarcely be doubted that this compound contains water.

To the above statements $M$. Figuier has made the following additions, which we translate at length :--

If to these considerations it be added, that the theory of M. Dumas was proposed at the period in which electro-chemical opinions were in highest favour, and that thus circumstanced he was guided especially by the analogy of the composition then attributed to the amalgam of ammonium (considered as a combination of azoturet of potassium and ammonia); and if it also be remarked, that analysis sufficiently agrees with this point of view, we shall probably be led to think that the ancient opinion of Proust and Berthollet is still the more probable one.

I am, however, continues M. Figuier, far from believing that these are the last words which will arise on this occasion. On all occasions, when the true nature of a compound containing ammonia is discussed, too much attention and reserve cannot be exerted. Some chemists will be tempted to see combinations of amide in these various kinds of fulminating gold, others may discover compounds obtained by the substitution of oxide of gold for the hydrogen of the ammonia; but I am of opinion that we ought not to be too much pre-occupied with these questions, which will be naturally resolved, with many others, when we possess more certain knowledge of the constitution of ammoniacal compounds.-Ann. de Ch. et de Phys., Juillet 1844.

ON THE TEROXIDE OF GOLD. BY M. FIGUIER.

Analysis of the Protoxide of Gold.-After trying various modes of analysis, such as reducing the oxide by hydrogen, and decomposition by hydrochloric acid, the author ascertained that the mere action of heat on this oxide was the most exact and ready method of analysis. Having determined by previous trial the accuracy of this process in analysing the tritoxide of gold, the author repeatedly found the number indicated by theory within the first place of decimals, and this, moreover, confirms the accuracy of the atomic weight of gold as determined by Berzelius. 'The following is the simple method of analysis adopted :-an indeterminate quantity of the oxide, but amounting to nearly 15 grains, was put into a very narrow glass tube, one end of which was blown into a bulb. Allowance was made by calculation for the small quantity of air contained in the tube, and as its capacity never exceeded about 1.5 cubic inch, it will be seen that the error resulting from the uncertainty of the temperature will entirely disappear on account of the smallness of the quantity of the air. The 
oxygen was received over water, and the metal weighed after calcination.

Four analyses of the protoxide of gold dried in vacuo, and obtained by different processes, were performed; in the first two experiments the protoxide was obtained with nitrate of mercury ; the third from protoxide obtained by potash from the chloride; the fourth from tritoxide and potash. In the last two cases the gold was treated before weighing with hydrochloric acid ; for the oxide thus obtained always retains a little alkaline sesquicarbonate, which is not removed by washing.

The volume of oxygen obtained, reduced to weight, gave the following results as the composition of the protoxide of gold in 100 parts :--

$$
\begin{array}{lrrrr}
\text { Oxygen.. } & 3.95 & 3.85 & 3.52 & 3.78 \\
\text { Gold... } & \frac{96.05}{100^{\circ}} & \frac{96^{\circ} 15}{100^{\circ}} & \frac{96^{\circ} 48}{100^{\circ}} & \frac{96.22}{100^{\circ}}
\end{array}
$$

The mean of which gives

$$
\begin{array}{lr}
\text { Oxygen.. } & 3 \cdot 77 \\
\text { Gold.... } & \frac{96^{2} 23}{100^{\circ}}
\end{array}
$$

M. Figuier considers the protoxide of gold as composed of

One equivalent of oxygen .. 100

One equivalent of gold .... 2486

\section{PROPERTIES OF OPIANIC ACID.}

M. Wöhler states that opianic acid crystallizes in small slender prisms, often as arborizations and usually reticulated. It is colourless, though it is not always obtainable without a slight yellow tint; it is but slightly soluble in cold water, but very readily in hot, so that a saturated boiling solution becomes almost one mass by cooling; it is also soluble in alcohol and in xther; it fuses at $284^{\circ}$ without losing water; it rises up the sides of the retort when heated in one, and distils without being properly volatilized; when heated in the open air it smokes, and volatilizes with an aromatic odour, somewhat resembling vanilla, and is very much like that which narcotina gives out when decomposed. The vapour is inflammable and burns with a sooty flame.

Opianic acid which has been melted by heat remains soft and transparent several hours after it has become cold, and may be drawn out into threads like turpentine. It afterwards begins to become opake and hardens at the surface, so slowly, however, that in pieces of considerable size a vitrified portion remains, as happens with arsenious acid. When examined in this state by the microscope, no well-characterized crystallization is perceptible in the opake hard portion; and it is very remarkable that the acid has become insoluble in water, alcohol or dilute alkaline solutions. If it be put into water while it is transparent and be then heated, it becomes milk-white in an instant; on boiling it is cunverted into an earthy-white mass, a very small portion of which is dissolved and deposits on cooling in 